\title{
“O CHARLATÃO” E A TEORIA DO CONTO
}

Augusto Machado Paim ${ }^{1}$

RESUMO: Este trabalho utiliza as teorias do conto de Cortázar e Piglia, além de instrumentos da narratologia para analisar o conto "O charlatão", do escritor português Miguel Torga. Trata-se de um autor pouco estudado, mas cuja obra permite a elaboração de reflexões sobre a própria teoria do conto. Destaca-se o uso do relato hipodiegético e da estrutura mise en abyme.

PALAVRAS-CHAVE: Miguel Torga; "O charlatão"; teorias do conto; narratologia; autoficção.

\section{“O CHARLATÃO” AND THE THEORY OF SHORT STORY}

\begin{abstract}
This work uses the theories of short story by Cortázar and Piglia and the science of narratology in order to analyze the short story "O charlatão", written by the Portuguese writer Miguel Torga. His tale allows a reflection itself on the theory of short stories, bringing up the use of structures like mise en abyme.
\end{abstract}

KEYWORDS: Miguel Torga; "O Charlatão"; theories of short story; narratology; self-fiction.

\footnotetext{
${ }^{1}$ Aluno do Mestrado em Escrita Criativa do Programa de Pós-Graduação em Letras da Pontifícia Universidade Católica do Rio Grande do Sul (PUCRS).
} 
Miguel Torga é o pseudônimo do escritor português Adolfo Correia da Rocha. Nascido em São Martinho de Anta, em 1907, e falecido em Coimbra, em 1995, Torga tornou-se um dos escritores mais premiados e profícuos do século 20. Escreveu poesia, teatro e prosa. Nesta última categoria, sua produção abrangeu gêneros como romance, conto e ensaio, mostrando-se assim um caso exemplar para a discussão das fronteiras entre os gêneros literários.

Aqui trabalharemos um dos contos de Miguel Torga, "O charlatão", que foi publicado em 1942, no volume Rua. O objetivo da análise é entender como o autor português discute a poética do conto enquanto gênero a partir de seu trabalho ficcional. Também faremos apreciações sobre as estratégias discursivas do enunciador do texto literário em questão.

Antes de tudo, precisamos falar sobre esse gênero narrativo tão associado à cultura pós-moderna.

\section{Do romance ao conto}

Para poder falar de conto, Cortázar estabelece uma comparação com o romance, no ensaio "Alguns aspectos do conto".

Para se entender o caráter peculiar do conto, costuma-se compará-lo com o romance, gênero muito mais popular, sobre o qual abundam as preceptísticas. Assinala-se, por exemplo, que o romance se desenvolve no papel, e, portanto, no tempo de leitura, sem outros limites que o esgotamento da matéria romanceada; por sua vez, o conto parte da noção de limite, e, em primeiro lugar, de limite físico, de tal modo que, na França, quando um conto ultrapassa as vinte páginas, toma já o nome de nouvelle, gênero a cavaleiro entre o conto e o romance propriamente dito. Nesse sentido, o romance e o conto se deixam comparar analogicamente com o cinema e a fotografia, na medida em que um filme é em princípio uma 'ordem aberta', romanesca, enquanto que uma fotografia bem realizada pressupõe uma justa limitação prévia, imposta em parte pelo reduzido campo que a câmara abrange e pela forma com que o fotógrafo utiliza esteticamente essa limitação. (CORTÁZAR, 1993, p. 151).

Em outro trecho, Cortázar compara o romance e o conto a uma luta de boxe: "Um escritor argentino, muito amigo do boxe, dizia-me que nesse combate que se trava entre um texto apaixonante e o leitor, o romance ganha sempre por pontos, enquanto que o conto deve ganhar por knock-out." (idem, p. 152). Ainda que as duas associações (com o boxe e com a fotografia e o cinema) possam ser problematizadas por uma análise mais aprofunda- 
da, elas servem para evidenciar dois dos principais elementos estruturais do conto enquanto gênero.

Segundo Cortázar, só se pode falar de conto a partir das noções de significação, de intensidade e de tensão.

Para o crítico alemão Helmut Bonheim:

Esta limitação de extensão arrastou outras limitações que tendem a ser observadas: um reduzido elenco de personagens, um esquema temporal restrito, uma acção simples ou pelo menos apenas poucas acções separadas, e uma unidade de técnica e de tom [...] que o romance é muito menos capaz de manter. (BONHEIM, 1982, p. 166).

Outros teóricos trabalham com conceitos diversos associados ao gênero conto. $\mathrm{O}$ escritor estadunidense Edgar Allan Poe, por exemplo, fala em uma teoria da unidade de efeito. Já o argentino Ricardo Piglia diz que o conto sempre apresenta duas histórias: o texto e o subtexto. Para sintetizar, o professor português Carlos Reis traz uma definição do gênero que abarca as origens no conto popular anônimo:

Conto: Género literário de origem remota, concretizando uma comunicação narrativa em prosa relativamente simples e de curta extensão, herdada de formas ancestrais (lenda, saga, ditado, etc); elaborando as categorias da narrativa em função de um princípio de concentração, o conto literário distingue-se de outros gêneros pela linear elementaridade das suas ações, personagens e tempos. ${ }^{2}$

O conto é hoje considerado por muitos estudiosos o gênero literário da época em que vivemos. Ele possui características (a principal delas, a brevidade) que parecem se adequar bem ao tempo da pós-modernidade. É necessário dizer ainda que o conto tem sua origem na oralidade. Nasceu das narrativas populares anônimas e de cunho oral. É por isso que até hoje conserva esse aspecto da linguagem falada.

O especialista alemão André Jolles utiliza o conceito de "formas simples":

Formas que não são apreendidas nem pela estilística, nem pela retórica, nem pela poética, nem mesmo pela 'escrita', talvez; que não se tornam verdadeiras obras de arte, embora façam parte da arte; que não constituem poemas, embora sejam poesia; em suma, aquelas formas a que se dão comumente os nomes de Legenda, Saga, Mito, Adivinha, Ditado, Caso, Memorável, Conto ou Chiste. (JOLLES, 1976, p. 20).

\footnotetext{
2 Definição apresentada durante a aula de 11 de novembro de 2011, na disciplina Tópicos de Literaturas Lusófonas, ministrada pelo professor Carlos Reis na Pontifícia Universidade Católica do Rio Grande do Sul (PUCRS).
} 
O conto aparece ao lado de gêneros cujo tempo é mítico (como a epopeia). Afinal, desde sua origem encontra-se no conto essa função axial de explicação e orientação de comportamentos $^{3}$. Essa função persiste até hoje. Na nossa visão, o conto pós-moderno continua tentando explicar a nossa sociedade, através de técnicas literárias como a fragmentação e a multilinearidade. Os recursos são diferentes, porque a sociedade é diferente, mas a intenção mitificadora ainda está lá.

\section{"O charlatão"}

Tendo em mente esse conjunto de reflexões, vamos analisar agora o conto de Miguel Torga. Trata-se de uma narrativa sobre a arte de narrar. Ao menos, esse é o seu subtexto, a sua segunda história, conforme conceituação de Piglia. Já a primeira história é a de Balsemão, um vendedor de feira que, de pé sobre uma cadeira, tenta convencer uma plateia de curiosos a comprarem seus produtos. O texto já começa com a fala do vendedor:

- Quando qualquer de V. Ex.as, às quatro horas da manhã, arrancado brutalmente dos braços de Morfeu por uma guinada do dente do siso, se vir desamparado e desgraçado, dirá então com amargura: - Razão tinha o amigo Balsemão ao microfone! Comprasse eu um tubo daqueles famosos comprimidos, e não estaria agora aqui a sofrer como um cão! — Dores reumáticas ou diáticas, nevralgias, enxaquecas, cólicas e pontadas tudo este maravilhoso remédio alivia instantâneamente, isto é: num abrir e fechar de olhos. (TORGA, 1985, p. 153).

Assumindo-se esse como um texto metalinguístico, podemos ler já aí uma postulação da literatura como phármakon ${ }^{4}$, um remédio que tanto pode curar quanto fazer adoecer (tendo-se em vista a procedência duvidosa das mercadorias comercializadas por um vendedor de feira). Igualmente, a escolha da profissão do personagem é um elemento importante para a construção do subtexto. Parece-nos assim possível pensar na aproximação entre as imagens do escritor e do vendedor: ambos manipulam seus discursos de maneira argumentativa, visando à sedução. Nenhum dos dois utiliza a linguagem de maneira inocente. Da mesma forma, se pensarmos que o vendedor comercializa pequenas utilidades domésticas, podemos refletir sobre o papel (e a função) exercida pela literatura em nossas vidas.

\footnotetext{
3 A noção de subtexto parece advir da ideia de "moral da história", característica dos contos populares, cujo objetivo era educar e moralizar as crianças dentro de uma estrutura social e cultural.

${ }^{4} \mathrm{O}$ francês Jacques Derrida trabalha esse conceito de escrita como phármakon em sua obra A farmácia de Platão.
} 
Em relação ao estilo, notamos a ocorrência frequente do discurso indireto livre, como no trecho:

E trapaceiros, daí a nada, passavam a ser os honrados indivíduos que todos os da roda consideravam pessoas de bem. Agora ele?! Pelo amor de Deus! Quem é que tinha a coragem de vir assim honestamente explicar os fatos, receber sugestões, pôr-se, numa palavra, em contacto direto com a massa dos humildes? Charlatão! Sempre a mesmíssima coisa! Sempre a costumada ingratidão pátria pelos seus valores! (TORGA, 1985, p. 157).

O texto é narrado por um narrador heterodiegético, categoria que

designa uma particular relação narrativa: aquela em que o narrador relata uma história à qual é estranho, uma vez que não integra, nem integrou, como personagem, o universo diegético em questão. Assim, se distingue o narrador heterodiegético do narrador homodiegético (e também, naturalmente, do autodiegético), que justamente se caracteriza pelo fato de narrar uma história que conhece pela sua experiência de testemunha direta dessa história. (REIS \& LOPES, 1988, p. 121).

Essas definições, no entanto, não são estanques e devem ser analisadas segundo a dinâmica interna de cada texto. Em "O charlatão", por exemplo, vemos um narrador que atende a todas as exigências de um narrador heterodiegético, mas que, incrivelmente, parece ser, durante a leitura, um narrador homodiegético. O narrador de "O Charlatão" não é identificado. Sabemos apenas que ele é um dos curiosos presentes na roda em volta do vendedor - ou assim o texto nos dá a entender. É como se o narrador assumisse assim a condição do leitor de qualquer texto: ele (o narrador, o leitor) é um mero anônimo que interpreta.

De fato, o principal motivo para a existência desse narrador hetero-homodiegético é colocar o leitor dentro de uma perspectiva interpretativa. O narrador de "O Charlatão" está lá descrevendo Balsemão e tecendo comentários sobre o seu relato. É através dele que ficamos sabendo das estratégias discursivas adotadas pelo vendedor e do modo como elas afetam o público: "Da sua voz sugestiva, grave, difundida pelo ampliador, tirava quantas inflexões eram necessárias para encantar homens de todas as terras e feitios" (TORGA, 1985, p. 154). O narrador, portanto, tem a função de fazer comentários sobre as técnicas narrativas - não só as do vendedor, mas também subtextualmente as da arte literária em geral. Como neste trecho, que pode ser associado a uma discussão sobre o interesse literário:

Os tempos corriam mal. Deus sabe com que vontade quem tinha os precisos para o resto do ano os vinha vender por qualquer preço. Por isso, 
depois de duas lágrimas dadas ao balido saudoso duma ovelha, à mansidão dum porco criado a caldo, ou à brancura duma peça de linho fiada à luz da candeia em horas roubadas ao sono, era um alívio perder meia hora ali. Iam-se embora as tristezas, as canseiras, os cuidados, e a feira passava a ter o ar de festa que o coração de todos pedia. E não pensasse lá que acreditavam nas aldrabices que dizia do novo elixir! Quem?! Enfim, como eram só dez tostões... Às vezes, para um remedeio... (idem, p. 155).

Outro trecho deixa bem claro que todos os presentes à roda sabem da inutilidade dos produtos vendidos por Balsemão:

Não prestava, era a convicção geral. Mas aqueles olhos a fuzilar o mal e a curá-lo, aquele rato brando de quando em quando parado e atento às palavras do dono, aquela mão erguida ao alto como um destino, dobravam a vontade do mais pintado. (idem, p. 156).

Em outras palavras: a ficcionalização seduz. Ou melhor, a narrativização proposta pela literatura seduz. Dela não podemos fugir.

E assim, através da visão do narrador, vemos todas as artimanhas usadas pelo vendedor para conquistar e manter a atenção da plateia e vender seu produto. Como um escritor que utiliza as técnicas de escrita para conquistar a atenção do leitor e nos fazer comprar sua visão de mundo.

\section{Relato hipodiegético e mise en abyme}

Em certa altura, a guisa de conquistar a confiança do público, Balsemão propõe-se a contar uma história pessoal.

O silêncio de todos bastava-lhe como resposta. Simplesmente, aquele universal acordo quanto à sua dignidade moral e honestidade profissional tocava-lhe as fibras mais sensíveis do coração. Era um sentimental. E a esse respeito, até para amenizar a conversa, ia abrir-se com o seu fiel auditório, com o bom e generoso povo da sua terra. Ia contar o que nunca contara, nem gostava até de recordar. Mas, enfim, já agora... Porque debaixo daquela aparência de pessoa alegre, bem disposta e saudável, tinha tido também os seus dissabores e as suas aflições... Justamente por ser um emotivo, um banana! (idem, p. 158).

Eis aí um relato hipodiegético, situação em que "uma personagem da história, por qualquer razão, específica e condicionada por determinadas circunstâncias, é solicitada ou incumbida de contar outra história, que assim aparece embutida na primeira." (REIS \& LOPES, 2011, p. 292-3). Esse relato hipodiegético manifesta-se no conto de Torga no 
momento em que Balsemão começa a contar uma história de amor acontecida com ele. A partir daí, o leitor do conto passa a ler duas histórias: a que acompanhamos desde o início, ou seja, a de um vendedor que tenta comercializar seus produtos em uma feira, e a segunda ${ }^{5}$ (inserida dentro da primeira), na voz de Balsemão.

A segunda história é contada sem que se esqueça da primeira. Afinal, ele começa a contar a sua chegada a Lisboa, há vinte anos, vindo de Paris, e logo já a interrompe, dirigindo-se a alguém na platéia: "Quê?! O senhor não acredita que eu fui a Paris?! Olha, olha, não acredita! Sou um homem muito viajado, santinho! Está aqui o meu passaporte! Está aqui o meu passaporte. Queira examinar... Fava favor.” (TORGA, 1985, p. 158-159). Segue-se comentário do narrador:

Tinha de provar tudo. Como um professor atento à disciplina e às dúvidas da turma, mal alguém se mexia impaciente ou mostrava nos olhos uma névoa de incredulidade ou de incompreensão, estendia-lhe o documento elucidativo ou a palavra iluminada, a ajudá-lo! Só quando o auditório respirava entendimento e aceitação, sossegava e prosseguia. (idem, p. 159).

Há aí, portanto, um discurso metalinguístico desenvolvendo-se em paralelo ao enredo do conto. Chegamos mesmo a identificar a estrutura do mise en abyme:

A expressão francesa que designa este procedimento de representação narrativa anuncia expressivamente aquilo que nele se concretiza: numa narrativa (ou mais genericamente numa obra literária), observa-se a própria narrativa ou um dos seus aspectos significativos, como se no discurso se projetasse 'em profundidade' uma representação reduzida, ligeiramente alterada ou figurada da história em curso ou do seu desfecho. (REIS \& LOPES, 2011, p. 233).

Portanto, o discurso metalinguístico, característico da primeira história, aparece de tempos em tempos interrompendo a segunda história. Uma forma fragmentada de contar e, ao mesmo tempo, uma lembrança permanente da estrutura mise en abyme ${ }^{6}$.

\footnotetext{
${ }^{5} \mathrm{O}$ relato hipodiegético não pode ser confundido com a teoria de Piglia. Afinal, quando o escritor argentino diz que todo conto narra duas histórias, ele está dizendo que todo texto tem também um subtexto. No caso do relato hipodiegético, as duas histórias continuam no mesmo nível textual, e não subtextual. Ainda que o subtexto, nos casos em que há manifestação desse tipo de relato, tenda a surgir da relação entre essas duas histórias ou de sua vinculação com uma realidade externa ao conto.

${ }^{6}$ Essa técnica pode ser encontrada em inúmeras obras literárias. Um exemplo próximo é a narrativa Viagens na minha terra, do português Almeida Garrett.
} 


\section{O charlatão é um fingidor}

A narração de Balsemão prossegue. Ele conta que andava numa rua de Lisboa quando viu à janela, no sexto andar de um prédio, uma linda jovem. Movido pela paixão repentina, ele subiu correndo as escadas e bateu à porta do apartamento da moça. Um mês depois, eles se casaram.

Então, a narrativa da segunda história para. Balsemão tenta vender ao seu público um produto para o fígado. Na plateia, porém, não há ninguém interessado. Todos vão ficando impaciente. "Mas o timoneiro daquele barco humano conhecia o mar" (idem, p. 161), diz o narrador, e o relato prossegue.

A fala de Balsemão tem muitas interrupções. Como na literatura, essas digressões cumprem uma função na narrativa - pode ser que o trecho forneça dados que serão importantes mais adiante; ou pode significar apenas uma desaceleração na história para preparar a chegada de clímax. Como diz o narrador: "Uma das maneiras de se tomar o pulso à assistência era divagar um pouco. Havia sempre alguém mais insofrido que protestava. E a história, assim reclamada, tinha outro sabor." (idem, p. 164).

Enquanto Balsemão conta sua história, há na plateia um homem de Vila-Meã, que diz ter ouvido esse mesmo causo em Pombal. O narrador conta que "Apesar disso, [o de Vila-Meã] ficou. Sempre queria ver se a história a seguir seria a mesma." (idem, p. 158) Repentinamente, a história de Balsemão sofre uma reviravolta e assume um tom triste. O narrador observa: “O de Vila-Meã, pela calada, ia-o observando. Até ali a história era exactamente a mesma. Quanto à tristeza que lhe ensombrava o rosto, não podia ser fingida. Certas coisas não se fingem... Não. Aquilo não podia ser tudo mentira...” (idem, p. 160).

Balsemão então passa a contar sobre os desacertos conjugais. Ao voltar prematuramente de uma viagem, ele percebeu uma luz acesa em sua casa. Tocou a campainha, a luz apagou-se. Ele percebe então que há algo errado. Ao seu público, conta que arrombou a porta com o ombro. Então a narrativa sofre novamente uma pausa: "Olhou o efeito das suas palavras, bebeu um gole de água, e levou ao rubro, numa só frase, o calor da multidão. — Para encurtar razões: meti três balas no corpo daquela miserável." (idem, p. 165) Trata-se de um trecho que mostra a perícia de Balsemão, sua destreza na arte de contar histórias.

Em seguida, ele conta que a mulher sobreviveu, e que o amante fugira pelos fundos. Nesse momento, o narrador observa: "Exactamente o que respondera em Pombal. E não... O suor que lhe escorria da testa não era do calor... A tarde até estava a refrescar...” (idem, p. 
166) Façamos agora uma aproximação desse comentário com o conhecido poema "Autopsicografia", de Fernando Pessoa:

\author{
O poeta é um fingidor. \\ Finge tão completamente \\ Que chega a fingir que é dor \\ A dor que deveras sente. \\ E os que lêem o que escreve, \\ $\mathrm{Na}$ dor lida sentem bem, \\ Não as duas que ele teve, \\ Mas só a que eles não têm. \\ E assim nas calhas de roda \\ Gira, a entreter a razão, \\ Esse comboio de corda \\ Que se chama coração.
}

O poema de Pessoa trata, em essência, do fenômeno da representação literária. O verso "O poeta é um fingidor" expressa o processo de ficcionalização dos temas de trabalho do poeta ou do prosador. Os três versos seguintes atestam o quanto se perde nessa transposição de um tema no caminho partindo da realidade para o terreno das representações. Afinal, a dor que o poeta sente não é a que ele põe em processo de representação, justamente porque esse processo prevê uma alteração do tema original como parte do seu procedimento de transposição (viver e narrar a vida vivida não são a mesma coisa). Ao mesmo tempo, enquanto representa uma dor, o poeta passa também a senti-la (porque a vida só adquire sentido ao ser narrada). Já a segunda estrofe trabalha a questão da leitura: entre o que o poeta quis representar e o que ele de fato representou, há ainda o elemento do que cada leitor é capaz de re-representar para si, a partir de suas próprias experiências de mundo. Por fim, a terceira estrofe ressalta esse jogo entre razão e emoção que caracteriza o labor literário.

Voltemos ao caso do conto de Miguel Torga. O que o personagem de Vila-Meã faz, em primeiro lugar, é questionar a veracidade do relato. Trata-se, afinal, de um causo contado repetidas vezes, e sempre através de técnicas de persuasão. No caso de ser uma história verídica, fica a pergunta: como pode Balsemão contar publicamente algo tão íntimo? E é ao fim, quando o personagem de Vila-Meã sugere que o suor que escorre da testa de Balsemão não é de calor, quiçá de nervosismo, que podemos reverberar os versos de Fernando Pessoa. Balsemão, como o de Vila-Meã bem percebe, está contando duas histórias: a da dor fingida e a da dor que deveras sente. A técnica, afinal, revela o sentimento, mas também o 
esconde. O poeta é um fingidor, ou seja, um charlatão. É por isso que, ao final, quando Balsemão termina sua sessão e vai embora (enquanto a multidão se dispersa), lemos: "Só na curva da morte, à Portela, é que o de Vila-Meã, ao vê-lo [Balsemão] passar, o reconheceu, lhe tirou o chapéu, e juntou à poalha do sol que caía a ternura duma palavra: — Coitado!” (TORGA, 1985, p. 168).

\section{O conto e o canto}

Miguel Torga demonstra maestria no domínio das fronteiras entre os gêneros literários. O conto "O Charlatão" é uma amostra disso.

- E vamos então continuar a nossa história. A minha, afinal de contas. É um grande romance, se eu soubesse escrever! Desgraçadamente, não sei. Conto... Conto, e a maior parte das vezes a sentir que toda a gente está a duvidar de mim... (idem, p. 162).

O que está representado nesse trecho, dito por Balsemão, senão as diferenças entre os gêneros "romance" e "conto" 7? Em primeiro lugar, vemos aí a questão da extensão. Balsemão sabe, afinal de contas, que a sua história é curta e, portanto, exige concentração de elementos. "Conto [aqui do verbo "contar"], e a maior parte das vezes a sentir que toda a gente está a duvidar de mim...” Sim, pois a pequena extensão exige uma tensão constante, um trabalho permanente de persuasão e construção de interesse narrativo. Algo que, em um romance, pode estar mais diluído por centenas de páginas.

Enquanto conta sua história infeliz, Balsemão faz uma interrupção necessária para alívio de tensão. Imita um beijo de mulher. "O fiel auditório ria da beijoca. Mas ele não se queria demorar ali." (idem, p. 163, grifo nosso) Estão aí representados os princípios da essencialidade e da manipulação temporal. Ou, melhor: vemos nesse conto de Torga todos os elementos considerados por Cortázar como característicos do conto enquanto gênero: significação, intensidade e tensão.

Mais adiante, quando Balsemão termina de contar sua história, o narrador diz: "Passado o calafrio do desfecho inesperado, começou a fazer-se dentro de cada um a crítica lógica da história. E alguns sorrisos incrédulos afloraram à tona de alguns rostos." (idem, p. 166) Torga traz à tona a questão da importância do final para uma narrativa de fôlego curto. E ele o faz mostrando a dificuldade, mesmo para um narrador experiente, de manter

\footnotetext{
${ }^{7}$ Esse trecho é ainda mais significativo se lembrarmos que Bakhtin situa o romance no âmbito da escrita e que o conto é um gênero de origem oral.
} 
o interesse narrativo. "Não havia dúvida nenhuma que a atenção do público descera com o fim da narrativa. Aquele homem, porém, era um prodígio de tenacidade. [...] Tempo perdido. O lume apagara-se na lareira." (idem, p. 167).

Para finalizar, um apontamento final. Afirmamos que o conto $O$ charlatão, de Miguel Torga, constrói-se a partir da estrutura do relato hipodiegético, ou seja, que há uma história (a de Balsemão vendendo seus produtos na feira) trazendo de si uma outra história (o caso amoroso de fundo romanesco contado por Balsemão). Essa estrutura é por si uma estratégia narrativa e, com isso, quer dizer algo, quer provocar certo efeito. Dissemos também que o subtexto do conto de Torga subjaz a questão da metalinguagem, manifesta pelo uso do mise en abyme. Isso se dá através do narrador e do personagem de Vila-Meã, ambos responsáveis por tecer comentários sobre os discursos de Balsemão. Com isso, parece que o autor está nos querendo também provocar reflexões sobre a arte narrativa.

Juntamos agora as duas observações para notar que: 1) a narrativa de Balsemão constrói-se a partir da oralidade (mesmo que seja um discurso representado em prosa, o fundamento dele é oral, ou seja, é alguém que fala para um público usando a palavra falada) 2) a narrativa de Torga (a história que inclui a segunda história) é escrita. Temos assim esse contraponto (ou aproximação) entre a narrativa oral e a escrita. Esse parece ser um tópico importante levantado pelo conto.

$\mathrm{Na}$ história da literatura, vemos que a poesia surge da oralidade, e a epopéia (bem como outros gêneros antigos) desenvolve-se também a partir da palavra declamada. Como diz Bakhtin:

Todos estes gêneros [epopeia, poesia, tragédia etc.], ou em todo caso, os seus elementos principais, são bem mais velhos do que a escritura e o livro. Ainda conservam nos dias de hoje, em maior ou menor grau, sua antiga natureza oral e declamatória. Ao lado dos grandes gêneros, só o romance é mais jovem do que a escritura e os livros, e só ele está organicamente adaptado às novas formas de percepção silenciosa, ou seja, à leitura. (BAKHTIN, 1990, p. 397).

Vejamos agora as palavras do escritor português José Saramago. Ele acredita que o romance contemporâneo está vivendo o caminho inverso, de retorno a esse ritmo poético oral descrito por Bakhtin. Diz Saramago:

Falo, sim, de um tempo poético, feito de ritmos, de suspensões, um tempo simultaneamente linear e labiríntico, instável, movediço, tempo com as suas leis próprias, um fluxo verbal que transporta uma duração e que uma duração por sua vez transporta, fluindo e refluindo como uma maré entre dois continentes. Este, repito, é o tempo poético, pertencente 
à recitação e ao canto, aproveita todas as possibilidades expressivas do andamento, do compasso e da coloratura, é melismático ou silábico, longo, breve, instantâneo. De um tempo assim entendido é minha ambição que vivam as ficções que vou inventando, consciente de que vou querendo, mais e mais, aproximar-me da estrutura de um poema que, sendo expansão pura, se mantivesse fisicamente coerente. (SARAMAGO, 1994, p. 121-122).

Mais adiante, comentando o prognóstico de especialistas de que o romance é um gênero fadado ao fim, Saramago prevê o surgimento de uma nova forma:

Mas este mesmo romance, que assim pareço estar condenado, contém acaso em si, e já nos seus diferentes e actuais avatares, a aberta possibilidade de se transformar no lugar literário (propositadamente digo lugar, e não género) capaz de receber como um grande, convulso e sonoro mar, os afluentes torrenciais da poesia, do drama, do ensaio, e também da ciência e da filosofia, tornando-se expressão de um conhecimento, de uma sabedoria, de uma cosmovisão, como o foram, para o seu tempo, os poemas da antiguidade clássica. (SARAMAGO, 1994, p. 122).

Saramago, portanto, imagina a evolução do romance contemporâneo para uma nova forma de canto, de narrativa oral dentro da narrativa escrita. Ora, por acaso não seria isso que temos representado no conto de Miguel Torga?

Com isso concluímos que "O charlatão" não é apenas uma grande narrativa, mas também uma habilidosa reflexão sobre as teorias do conto e dos gêneros literários, ainda mais habilidosa por ser conduzida fora do campo ensaístico, ou seja, através da ficção.

\section{Bibliografia}

BAKHTIN, Mikhail. Epopeia e romance. In: "Questões de literatura e de estética - a teoria do romance" 2a edição. São Paulo : HUCITEC, 1990.

BONHEIM, H. The Narrative Modes. Techniques of the Short Story. Cambridge : D. S. Brewer, 1982.

CORTÁZAR, Julio. Valise de cronópio. 2a edição. São Paulo : Perspectiva, 1993.

JOLLES, A. Formas Simples. São Paulo : Cultrix, 1976.

REIS, Carlos; LOPES, Ana Cristina M. Dicionário de Narratologia. $7^{\mathrm{a}}$ ed., $2^{\mathrm{a}}$ reimp. Edições Almedina : Coimbra, 2011.

Dicionário de Teoria da Narrativa. São Paulo : Editora Ática, 1988. 
SARAMAGO, José. Do canto ao romance, do romance ao canto. Bulletin of Hispanic Studies, LXXI, 1 (1994).

O autor como narrador. In "Ler”, 38, Primavera-Verão, 1997.

TORGA, Miguel. Rua. $5^{\text {a }}$ edição. Coimbra : Edição do Autor, 1985.

Artigo recebido em: 28 de Março de 2012.

Artigo aprovado em: 31 de Outubro de 2012. 